\title{
PREOPERATIVE AND PATHOLOGICAL STAGING OF NSCLC: RETROSPECTIVE ANALYSIS OF 291 CASES
}

\author{
Riad Naim Younes ${ }^{1 *}$, Fabio Augusto Barros Schutz ${ }^{2}$, Jefferson Luiz Gross ${ }^{3}$ \\ Study conducted at the Department of Thoracic Surgery, Hospital AC Camargo and Hospital Sírio-Libanes, Sao Paulo, SP
}

*Correspondence:

Hospital Sírio Libanês

Rua Dona Adma Jafet, 91

Sao Paulo (SP)

CEP: 01308-050

Tel: (11) 3257-2808

rnyounes@yahoo.com

\begin{abstract}
SUMMARY
Овлестіve. The objective of this study was to evaluate the accuracy of preoperative clinical staging with computed tomography in predicting the correct pathological stage.

MEtHods. Medical records of non-small cell lung cancer (NSCLC) patients treated, from 1990 to 2005 were reviewed. Clinical stage was based on routine preoperative clinical and imaging evaluation. Positron emission tomography was not routinely performed. Suspected lesions, that would preclude a surgical resection, were pathologically confirmed. The pathological stage was based on final postoperative or biopsy pathological assessment. A correlation table between clinical and pathological stages was generated. Cohen's kappa index, sensitivity, specificity, positive and negative predictive values and accuracy were calculated.

Results. Records of 291 patients were reviewed. Clinical stages Ia, Ib, Ila, IIb, IIIa, IIIb and IV were found respectively in $8.9 \%, 31.9 \%, 0.3 \%, 18.6 \%, 25.4 \%, 11 \%$ and $3.8 \%$. Pathological staging was different from clinical staging in 33\% (15\% were upstaged and $18 \%$ downstaged). Sensitivity, specificity, positive and negative predictive values and accuracy for clinical staging were 78\%, 69\%, 82\%, 64\% and 67\%, respectively. Cohen's kappa index was $0.574(\mathrm{P}<0.001)$. ConcLusion. Preoperative clinical staging presents limited efficacy for the correct staging of NSCLC patients from this sample of Brazilian population.
\end{abstract}

KEY WORDS: Lung neoplasms. Neoplasm staging. Tomography, Spiral computed.

\section{INTRODUCTION}

Lung cancer is one of the most common cancers worldwide. According to the last world estimate, more than $1,300,000$ new cases occurred in $2002^{1}$. A total of 215,020 new cases were expected in the United States in 2008. Lung cancer is the second most common cancer for both men and women. It was also estimated that in 2008, lung cancer would be the leading cause of death from neoplasia (161,840 deaths) in the United States, accounting for approximately $30 \%$ of all cancer deaths. ${ }^{2}$ In Brazil, according to the Instituto Nacional do Câncer (INCA), it was estimated that 27,270 new cases of lung cancer would be diagnosed in 2008. ${ }^{3}$

Lung cancer remains a highly lethal disease. The five-year overall survival for all stages is approximately 15\%,2,4 whereas patients submitted to surgical resection present a five-year overall survival rate of approximately 40\%. ${ }^{4}$ Younes et al. (2004) reported in a Brazilian population, a five-year overall survival of $28 \% .{ }^{5}$ Despite all efforts to attain correct clinical staging and subsequent radical surgical resection, overall survival rates for lung cancer, according to stage, are significantly lower than those observed in other primary malignant tumors. ${ }^{6}$ One of the largest retrospective Brazilian series, with 737 patients, showed overall median survival of $95,78,73,23,16$ and 10 months, respectively, for stages Ib, IIa, IIb, IIIa, IIIb and IV. ${ }^{5}$ In Brazil, median overall survival, in a population with metastatic lung cancer outside of clinical trials, was reported as being 9.7 months. $^{7}$

The correct staging of patients is essential, as cancer treatment is directed according to the stage of the disease. Patients with advanced disease could be spared from unnecessary invasive procedures (i.e. thoracotomy) and patients with true early disease would not be spared from a potentially curative treatment. Important considerations in the preoperative assessment of patients with lung cancer include correct staging of the tumor (location and anatomical relation to bronchi, invasion of the thoracic wall and mediastinal structures and pleural implants) and the lymph nodes (presence or absence of involved lymph nodes and their correct location). Pathological stage has been proven to be the most important prognostic factor in lung cancer. However, this can only be accurately determined, usually after pathological confirmation. The correct clinical staging is also important for the

1. Doutorado (PhD); Professor Livre Docente pela Universidade de São Paulo - USP; Thoracic Surgeon, Department of Thoracic Surgery, Hospital AC Camargo and Physician-in-Chief and Director of Advanced Center of Thoracic Diseases at Hospital Sírio Libanês, São Paulo, SP

2. Medical Oncologist, Department of Thoracic Surgery, Hospital AC Camargo and Medical Oncologist, Oncology Center at Hospital Sírio Libanês, São Paulo, SP

3. Doutorado (PhD) - Thoracic Surgeon, Department of Thoracic Surgery, Hospital AC Camargo, São Paulo, SP 
appropriate decision about complementary treatments (neoadjuvant or adjuvant) to surgical resection. Therefore, efforts for the improvement of clinical staging should be made.

Extensive involvement of mediastinal lymph nodes, as well as the detection of pleural effusion and/or pleural implants or distant metastatic disease, usually precludes radical surgical procedures. Therefore, all efforts must be made for the correct selection of patients that are candidates for radical surgery. Preoperative staging is routinely carried out through chest and abdominal computed tomography (CT), bone scan, magnetic resonance image (MRI) of the brain, bronchoscopy and mediastinoscopy. Recently, Positron Emission Tomography (PET)-CT has been used to stage patients with lung cancer. Despite the recent advances in clinical staging, there is no absolute concordance between clinical and pathological stage. The latter is more accurate, but can be only determined after surgery. Santos et al. (2007) published a Brazilian series of 92 patients, submitted to surgical resection (clinical stages from la to $\mathrm{llb}$ ), comparing clinical and pathological stages. It was observed that the concordance between clinical and pathological stage was low (approximately $60 \%$ ), and patients were more often downstaged at preoperative evaluation. ${ }^{8}$ The difficulty in predicting lymph node metastases with computed tomography is presumed to be responsible for the low concordance, especially in Brazil, a country with high incidence of infectious diseases like tuberculosis.

The objective of the present study was to evaluate the efficacy of the preoperative clinical staging with computed tomography (CT), when compared to pathological staging, in a Brazilian patient population.

\section{Methods}

This is a retrospective review of non-small cell lung cancer (NSCLC) patients submitted to surgical treatment at the Department of Thoracic Surgery at Hospital do Cancer A. C. Camargo, São Paulo, Brazil, from 1990 to 2005. All patients had a confirmed histological diagnosis of NSCLC and had been submitted to routine staging and definitive surgical resection of the lung and systematic mediastinal lymph node dissection. Patients submitted to neoadjuvant chemotherapy or radiotherapy were excluded from analysis. The staging classification of the current analysis was carried out based on the criteria established by the American Joint Committee on Cancer (AJCC) of $2002 .{ }^{9}$ All patients were submitted to the same preoperative staging procedures. Imaging assessment included CT scan of chest and upper abdomen, bone scan scintigraphy and brain CT or MRI, and bronchoscopy. Blood tests included: whole blood count, coagulation tests, creatinine, urea, alkaline phosphatase, lactic dehydrogenase, bilirubins and others, according to clinical indication.

Clinical staging was considered to be the one based on preoperative imaging. Presence of suspected mediastinal lymph nodes (smallest diameter $>1 \mathrm{~cm}$ ), which would eventually contraindicate surgical resection, was confirmed by direct biopsy. When distant metastatic disease was suspected, pathological confirmation through a biopsy procedure was necessary.

As a routine in our service, radical surgical procedure consisted of lung resection by lobectomy or pneumonectomy (segmentectomy or wedge resections were reserved for patients with poor cardio-pulmonary function) and systematic mediastinal lymph node dissection. Pathological staging was considered the gold standard for stage determination.

For statistical analysis a correlation table between clinical and pathological staging frequency was generated. Cohen's kappa index was used to determine the power of concordance between clinical and pathological stages. (10) Sensitivity, specificity, negative predictive value, positive predictive value and accuracy were calculated for clinical staging. Differences were considered significant for the value of $p<0.05$.

\section{RESULTS}

A total of 291 cases of non-small cell lung cancer submitted to surgery were reviewed. The baseline patient characteristics are presented in Table 1 . The correlation between clinical and pathological staging is shown in Table 2 and Figure 1. It was observed that $67 \%$ of the patients $(n=194)$ presented the same clinical and pathological stages. Therefore, 33\% ( $n=$ 97) of patients had a clinical stage that was different from the pathological stage, with $15 \%$ being upstaged $(n=43)$ and $18 \%$ downstaged ( $n=54$ ) by clinical staging procedures. Patients that were upstaged were considered as having a false-positive preoperative staging and those downstaged as a false-negative preoperative staging.

Sensitivity and specificity attributed to preoperative staging were, respectively, $78 \%$ and $69 \%$. Positive and negative predictive values were, respectively, $82 \%$ and $64 \%$, and the accuracy was $67 \%$.

Among patients with preoperative staging la $(n=26), 92 \%$ presented with the same pathological stage and only two patients (8\%) presented a pathological stage higher than la (pathological stages Ib and IIla).

The patients with preoperative stage $\mathrm{lb}$ represented the highest proportion of patients in the present study $(n=93)$. Preoperative staging was able to correctly predict pathological stage in $75 \%$ of cases. In the remaining stage Ib patients, a lower stage and a higher stage were observed at surgery, $5 \%$ and $20 \%$, respectively. Discordant pathological stages were as follows: la $=5 \%, \mathrm{Ilb}=4 \%, \mathrm{IIa}=11 \%, \mathrm{IIb}=1 \%$ and $\mathrm{IV}=4 \%$. On the other hand, patients with preoperative stage Ila represented the lowest proportion of patients, with only one individual, and pathological stage was coincident with clinical stage.

\begin{tabular}{lc}
\hline \multicolumn{2}{c}{ Table 1 - Baseline patient characteristics } \\
\hline Total patients included $(\mathrm{n})$ & 291 \\
$\quad$ Male (\%) & $75.6 \%$ \\
Female (\%) & $24.4 \%$ \\
Median age (range) & $1.5(25.4-81.8)$ \\
Ever smokers ( $\mathrm{n})$ & 154 \\
$\quad$ Median pack/years (range) & $40(2.5-92)$ \\
Performance status - $\mathrm{n}(\%)$ & \\
$90-100$ & $132(45.4 \%)$ \\
80 & $48(16.5 \%)$ \\
$<80$ & $57(19.6 \%)$ \\
Not specified in chart & $54(18.5 \%)$ \\
\hline
\end{tabular}




\begin{tabular}{|c|c|c|c|c|c|c|c|}
\hline \multicolumn{8}{|c|}{ Preoperative staging } \\
\hline Pathological staging & $\begin{array}{c}\text { la } \\
\mathrm{n}=26\end{array}$ & $\begin{array}{c}\mathrm{lb} \\
\mathrm{n}=93\end{array}$ & $\begin{array}{c}\| l a \\
n=1\end{array}$ & $\begin{array}{c}\| \mathrm{lb} \\
\mathrm{n}=54\end{array}$ & $\begin{array}{c}\text { IIla } \\
\mathrm{n}=74\end{array}$ & $\begin{array}{c}\| l \mid b \\
n=32\end{array}$ & $\begin{array}{c}\text { IV } \\
\mathrm{n}=11\end{array}$ \\
\hline la & $24(92 \%)$ & $5(5 \%)$ & 0 & 0 & 0 & 0 & 0 \\
\hline $\mathrm{Ib}$ & $1(4 \%)$ & $69(75 \%)$ & 0 & $8(15 \%)$ & $14(19 \%)$ & $4(13 \%)$ & 0 \\
\hline Ila & 0 & 0 & $1(100 \%)$ & $1(2 \%)$ & 0 & $1(3 \%)$ & 0 \\
\hline$\| \mathrm{b}$ & 0 & $4(4 \%)$ & 0 & $23(43 \%)$ & $8(11 \%)$ & 0 & $1(9 \%)$ \\
\hline IIla & $1(4 \%)$ & $10(11 \%)$ & 0 & $19(35 \%)$ & $45(61 \%)$ & 0 & $1(9 \%)$ \\
\hline IIIb & 0 & $1(1 \%)$ & 0 & $3(5 \%)$ & $3(4 \%)$ & $23(71 \%)$ & 0 \\
\hline IV & 0 & $4(4 \%)$ & 0 & 0 & $4(5 \%)$ & $4(13 \%)$ & $9(82 \%)$ \\
\hline
\end{tabular}

Figura 1 - Patients' distribution for each pre-operative stage according to the partholofical stage

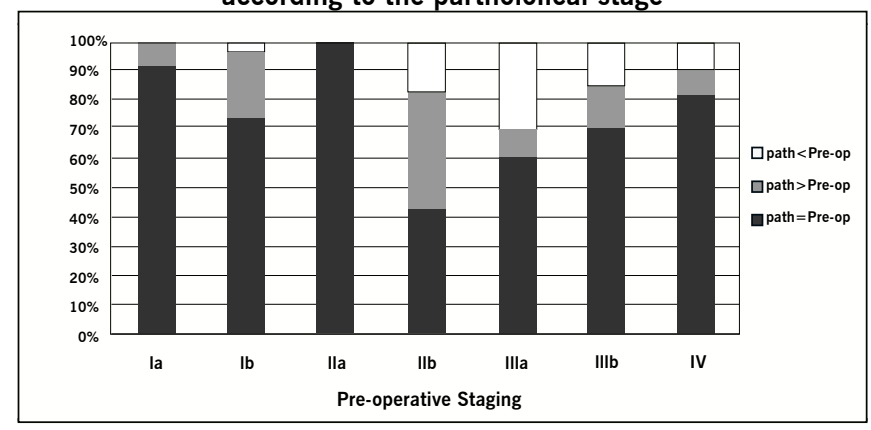

Legend: Path < Pre-op, Pathological stage lower than the pre-operative stage; Path > Pre-op, Pathological stage higher than the Pre-operative stage; Path = Pre-op, Pathological stage equal to the Pre-operative stage.

Patients with preoperative stage IIb were the group that most often presented discordance with the pathological stage. Of the 54 patients with preoperative stage IIb, only $43 \%$ of patients had the same pathological stage. Patients presented with higher pathological stage in 40\% (IIIa in 35\% and IIIb in 5\%), and $17 \%$ of patients presented with lower pathological stage (Ib in $15 \%$ and $\mathrm{ll}$ a in $2 \%$ ).

In patients with preoperative stage IIIa ( $n=74), 61 \%$ presented concordance with the pathological stage. The discordant pathological stages can be divided as follows: Ib in 19\%, IIb in $11 \%$, IIIb in $4 \%$ and IV in $5 \%$. In clinical stage IIIb $(\mathrm{n}=$ 34), $71 \%$ presented the same pathological stage. Patients that presented with different pathological stage were distributed as follows: Ib in 13\%, Ila in 3\% and IV in 13\%.

Patients with preoperative stage IV, with suspected metastatic sites at the preoperative staging exams, represented $4 \%$ ( $n=$ 11 ) of the total number of patients. In this group, we observed that two patients (pathological stage IIb and IIla) presented a pathological stage lower than IV when submitted to the diagnostic procedure of the suspected lesion.

The results of Cohen's analysis showed a kappa index of 0.574 (95\% confidence interval 0.538-0.610), with $p<0.001$.

\section{Discussion}

This is the largest Brazilian series (291 patients), to evaluate the efficacy of preoperative clinical staging in non-small cell lung cancer patients treated at a single institution. All patients were submitted to the same staging and treatment procedures. We observed a correlation of $67 \%$ between preoperative and pathological staging.

The present study showed sensitivity and specificity of $69 \%$ and $78 \%$, respectively. These values are compatible with those observed in medical literature. ${ }^{11-14}$ Lopez-Encuentra et al. (2005) published the largest series of patients. A concordance of $47 \%$ between clinical and pathological staging was found, being higher for stages la-lb, with $75 \%$ concordance. ${ }^{15}$ They also found that downstaging was more frequent than upstaging, similar to what was found in our series. Another series, also demonstrated an overall concordance of $48 \%$, with a higher rate in the earlier stages $^{16}$

A published meta-analysis, with 42 studies analyzing efficacy of the CT staging, showed an accuracy of $79 \%$ for the detection of positive mediastinal lymph nodes (sensitivity of $79 \%$ and specificity of $78 \%) .{ }^{17}$ Other more recent studies have also demonstrated non-satisfactory, and even lower, sensitivities (63 and 64\%) and specificities (57 and 62\%), with an accuracy of only $59 \% .18,19$

In the present series a statistically significant kappa index of 0.574 was found. This result demonstrates moderate concordance between clinical and pathological staging for the entire cohort. This finding is in accordance with previous published series. Santos et al. (2007) stratified patients with clinical stage la, Ib and IIb only $(n=92)$, and demonstrated a kappa index of $0.74,0.33$ and 0.41 , respectively (8). In the present series, the concordance rate was higher for earlier stages (la and Ib) as shown in Figure 1.

In our series, we found that patients with earlier clinical stage had a higher concordance with pathological stage. Patients with Ia and Ib stage were found to have a more advanced pathological stage in only 8 and $20 \%$, respectively. On the other hand, it is important to point out that $40 \%$ of patients with clinical stage IIb had in fact a more advanced pathological disease. These results highlight the importance of thorough mediastinal staging. 
Younes RN ET AL.

The retrospective nature of this series and the long time needed to collect the data limit a more comprehensive analysis. However, nowadays there is no enthusiasm for conducting a prospective study to evaluate the effectiveness of CT scan for NSCLC staging. Recent studies have shown that PET-CT scan can improve the efficacy of preoperative staging when added to CT scan. Unfortunately, PET-CT scan is not yet widely available in developing countries. An interesting and unanswered question is the effect of adding PET-CT scan to the CT scan in preoperative NSCLC staging on overall survival.

Most limitations of the correct preoperative clinical staging are related to the $\mathrm{N}$ stage. Several studies have demonstrated the low efficacy of the mediastinal staging with $\mathrm{CT}$, when compared to definitive pathological staging. ${ }^{11-14}$ Therefore, the systematic lymph node dissection of the mediastinum must be carried out routinely in all lung cancer resections, whenever possible. ${ }^{20}$

The T stage is important for clinical staging, and sometimes it is difficult to predict chest wall, pleural or mediastinal invasion, or even presence of other satellite nodules in the same lobe. These features are directly dependent on the resolution and technique of the CT scan used. However, considering the T stage alone, the concordance, between clinical and pathological stages was seen to be higher than in the $\mathrm{N}$ stage. It had been reported that the sensitivity and specificity of CT in distinguishing T3-4 from T1-2 was $63 \%$ and $84 \%$, whereas in distinguishing N2 from N0-1 it was $52 \%$ and $69 \%$, respectively. ${ }^{21}$ When the T stage is analyzed separately from the $\mathrm{N}$ stage, approximately $75 \%$ of patients had the same clinical and pathological T stage. On the other hand, $26 \%$ of patients classified as having clinically N0, in fact were found to have pathological N2. ${ }^{16}$

Thoracoscopy has been suggested to be more accurate for predicting the T stage. In a small series $(n=50)$, of NSCLC patients with negative mediastinoscopy, it was observed that thoracoscopic examination ruled out malignant pleural effusions (T4 stage) in 14\% patients with radiologically obvious effusions, and identified radiologically silent malignant pleural effusions in $6 \%$ patients. Thoracoscopy was able to correctly stage $88 \%$ of cases, whereas CT did so in $42 \% .{ }^{22}$ In our series patients were not submitted to routine thoracoscopy for staging.

CT scan estimates the probability of neoplastic involvement of lymph nodes through analysis of their size and/or location. Usually, the normal size of a mediastinal lymph node must not exceed $10 \mathrm{~mm}$ on its smallest axis. However, some benign lymph nodes, especially in the subcarinal region, might reach $15 \mathrm{~mm}$. Any other lymph nodes larger than this size are suspicious for malignancy. However, it is important to remember that, in some mediastinal regions, such as the pericardial fat, lymph nodes are normally not detected. Therefore, any lymph node perceivable in these locations must be considered abnormal.

It seems obvious that the larger the lymph node, the higher is its probability of being positive. However, McLoud et al. (1992) observed that $37 \%$ of the lymph nodes between 2 and $4 \mathrm{~cm}$ in size were simply hyperplastic, with no detectable metastases. ${ }^{19}$ Gdeedo et al. (1997) reported $29 \%$ of false-positive findings at the CT, as well as $12 \%$ of false-negative results. ${ }^{18}$ In the present series, we also observed a $15 \%$ rate of false-positive CT assessments of the total number of patients, whereas the rate of false-negative CT assessments was $18 \%$. Considering only the patients with IIIa or IIIb stages, which are usually due to $\mathrm{N}$ positive disease, we observed that the rate of false-positive CT assessments was $30 \%$ and $16 \%$, respectively. These results emphasize the importance of pathological confirmation of any suspicious lesion, be it a mediastinal lymph node or any abnormality elsewhere.

Recent CT techniques seem to improve the sensitivity and specificity of the method. Use of the helical CT with 3-mm thick slices and 5-mm slice intervals, during the early and late phases of contrast enhancement, allows the observation of certain characteristics in the lymph nodes that might help in the detection of lymph node metastases. It has been demonstrated that, regardless of size, lymph nodes with central hypodensity or hyperdense nodularity or areas of hyperdensity in the perilymph nodal fat tissue are capable of increasing the sensitivity and specificity to $97 \%$ and $100 \%$, respectively, decreasing the chance of false-positive and false-negative lymph nodes. In comparison, when only size of the lymph node is taken into account, sensitivity and specificity obtained were only $52 \%$ and $93 \%$, respectively. ${ }^{23}$

The discordance of the $\mathrm{M}$ stage is usually due to suspected metastatic disease (e.g. liver and adrenal gland nodules) that are found to be negative for carcinoma after pathological assessment. It has been observed that PET-CT is able to detect distant metastatic disease in approximately $20 \%$ of patients thought to be MO stage by $\mathrm{CT}^{24}$ In the present series, PET-CT was not routinely performed. The PET-CT is also important for clinical staging of mediastinal lymph nodes.

A very important factor for imprecision of clinical staging, or stage migration observed in our series, as well was in other previous studies, was the $\mathrm{N}$ stage. Mediastinal lymph nodes could be affected microscopically and not seen on clinical staging. On the other hand, some patients have preoperative enlarged, albeit benign lymph nodes. This is particularly frequent in geographic regions with high granulomatous or inflammatory mediastinal disease prevalence, ${ }^{25}$ as it occurs in Brazil.

\section{Conclusions}

In conclusion, preoperative clinical staging with CT scan presents a limited efficacy for the correct staging of patients, showing a significant proportion of false-negative and falsepositive results. The use of modern tomography equipment and experienced radiologists can improve the sensitivity and specificity of the method. Finally, the PET-CT is promising for the improvement of preoperative clinical staging.

\section{Conflict of interest: none}

\section{Resumo}

\section{ESTADIAMENTOS PRÉ-OPERATÓRIO E PATOLÓGICO DO CPNPC: ANÁLISE RETROSPECTIVA DE 291 CASOS}

OBJETIVO. O objetivo do presente estudo foi avaliar a eficácia do estadiamento clínico pré-operatório com tomografia computadorizada com o estadiamento patológico.

MÉTodos. Entre 1990 e 2005, foram revisados retrospectivamente os prontuários dos pacientes com câncer de 
pulmão não-pequenas células (CPNPC). O estágio clínico foi baseado em exames pré-operatórios de imagem. Tomografia por emissão de pósitrons não foi incluída na rotina de exames pré-operatórios. Lesões suspeitas, que contra-indicassem a ressecção cirúrgica curativa, foram confirmadas patologicamente. O estágio patológico foi considerado aquele baseado na análise patológica pós-operatória ou em biópsia de lesão suspeita. Foi gerada uma tabela de correlação entre estágio clínico e patológico. Foram calculados o índice kappa de Cohen, a sensibilidade, a especificidade, o valor preditivo positivo e negativo, e a acurácia.

RESUltados. 291 prontuários de pacientes foram revisados.

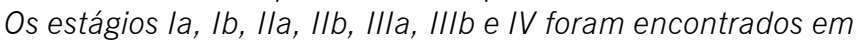
8,9\%, 31,9\%, 0,3\%, 18,6\%, 25,4\%, $11 \%$ e 3,8\%, respectivamente. Estágio patológico foi diferente do estágio clínico em 33\% dos pacientes (15\% foram sobre-estadiados e $18 \%$ sub-estadiados). Sensibilidade, especificidade, valor preditivo positivo e negativo, e acurácia foram 78\%,69\%, 82\%, 64\% e $67 \%$, respectivamente. O índice kappa de Cohen foi de $0,574(P<0,001)$.

CONClUSÃo. O estadiamento clínico pré-operatório apresenta eficácia limitada no estadiamento dos pacientes com CPNPC. [Rev Assoc Med Bras 2010; 56(2): 237-41]

UnITERmos: Neoplasias pulmonares. Carcinoma pulmonar de células não pequenas. Estadiamento de neoplasias. Tomografia computadorizada espiral.

\section{REFERENCES}

1. Parkin DM, Bray F, Ferlay J, Pisani P. Global cancer statistics, 2002. CA Cancer J Clin. 2005;55(2):74-108.

2. Jemal A, Siegel R, Ward E, Hao Y, Xu J, Murray T, et al. Cancer statistics, 2008. CA Cancer J Clin. 2008;58(2):71-96.

3. Ministério da Saúde. Secretaria de Atenção à Saúde. Instituto Nacional de Câncer. Coordenação de Prevenção e Vigilância de Câncer. Estimativas 2008: Incidência de câncer no Brasil. Rio de Janeiro: INCA; 2007.

4. Naruke T, Tsuchiya R, Kondo $H$, Asamura $H$. Prognosis and survival after resection for bronchogenic carcinoma based on the 1997 TNM-staging classification: the Japanese experience. Ann Thorac Surg. 2001;71(6):1759-64.

5. Younes RN, Deutsch F, Badra C, Gross J, Haddad F, Deheinzelin D. Nonsmall cell lung cancer: evaluation of 737 consecutive patients in a single institution. Rev Hosp Clin Fac Med São Paulo. 2004;59(3):119-27.

6. Spira A, Ettinger DS. Multidisciplinary management of lung cancer. N Engl J Med. 2004;350(4):379-92

7. Naime FF, Younes RN, Kersten BG, Anelli A, Beato CA, Andrade RM, et al. Metastatic non-small cell lung cancer in Brazil: treatment heterogeneity in routine clinical practice. Clinics. 2007;62(4):397-404.

8. Santos PA, Rocha RS, Pipkin M, Silveira ML, Cypel M, Rios JO, et al. Concordance between clinical and pathological staging in patients with stages I or II non-small cell lung cancer subjected to surgical treatment. J Bras Pneumol. 2007;33(6):647-54.
9. Greene FL, Page DL, Fleming ID, Fritz AG, Balch CM, Haller DG, Morrow M. AJCC Cancer staging handbook. $6^{\text {th }}$ ed. New York (NY): Springer-Verlag. 2002.

10. Landis JR, Koch GG. The measurement of observer agreement for categorical data. Biometrics. 1977;33(1):159-74.

11. Sioris T, Jarvenpaa R, Kuukasjarvi P, Helin H, Saarelainen S, Tarkka M. Comparison of computed tomography and systematic lymph node dissection in determining TNM and stage in non-small cell lung cancer. Eur J Cardiothorac Surg. 2003;23(3):403-8.

12. Fernando $\mathrm{HC}$, Goldstraw P. The accuracy of clinical evaluative intrathoracic staging in lung cancer as assessed by postsurgical pathologic staging. Cancer. 1990;65(11):2503-6.

13. Graham AN, Chan KJ, Pastorino U, Goldstraw P. Systematic nodal dissection in the intrathoracic staging of patients with non-small cell lung cancer. J Thorac Cardiovasc Surg. 1999;117(2):246-51.

14. Chong CF, Khoo KL, Lim TK, Chang AY, Lim HL, Lee CN, et al. Comparison of clinical with pathological nodal staging from systematic mediastinal lymph node dissection in early resectable non-small cell lung cancer. Singapore Med J. 2007;48(7):620-4.

15. Lopez-Encuentra A, Garcia-Lujan R, Rivas JJ, Rodriguez-Rodriguez J, Torres-Lanza J, Varela-Simo G. Comparison between clinical and pathologic staging in 2,994 cases of lung cancer. Ann Thorac Surg. 2005;79(3):974-9; discussion 9.

16. Cetinkaya E, Turna A, Yildiz P, Dodurgali R, Bedirhan MA, Gurses A, et al. Comparison of clinical and surgical-pathologic staging of the patients with non-small cell lung carcinoma. Eur J Cardiothorac Surg. 2002;22(6):1000-5.

17. Dales RE, Stark RM, Raman S. Computed tomography to stage lung cancer. Approaching a controversy using meta-analysis. Am Rev Respir Dis. 1990;141(5 Pt 1):1096-101.

18. Gdeedo A, Van Schil P, Corthouts B, Van Mieghem F, Van Meerbeeck J, Van Marck E. Prospective evaluation of computed tomography and mediastinoscopy in mediastinal lymph node staging. Eur Respir J. 1997;10(7):1547-51.

19. McLoud TC, Bourgouin PM, Greenberg RW, Kosiuk JP, Templeton PA, Shepard $\mathrm{JA}$, et al. Bronchogenic carcinoma: analysis of staging in the mediastinum with CT by correlative lymph node mapping and sampling. Radiology. 1992;182(2):319-23.

20. Robinson LA, Wagner H, Jr., Ruckdeschel JC. Treatment of stage IIIA non-small cell lung cancer. Chest. 2003;123(1 Suppl):202S-20S.

21. Webb WR, Gatsonis C, Zerhouni EA, Heelan RT, Glazer GM, Francis IR, et al. CT and MR imaging in staging non-small cell bronchogenic carcinoma: report of the Radiologic Diagnostic Oncology Group. Radiology. 1991;178(3):705-13.

22. Roberts JR, Blum MG, Arildsen R, Drinkwater DC Jr., Christian KR, Powers TA, et al. Prospective comparison of radiologic, thoracoscopic, and pathologic staging in patients with early non-small cell lung cancer. Ann Thorac Surg. 1999;68(4):1154-8.

23. Pirronti T, Macis G, Sallustio G, Minordi LM, Granone P, Vecchio FM, et al. Evaluation of the "N" factor in nonsmall cell lung cancer. Correlation between computerized tomography and pathologic anatomy. Radiol Med. 2000;99(5):340-6.

24. Rodriguez Fernandez A, Gomez Rio M, Llamas Elvira JM, Sanchez-Palencia Ramos A, Bellon Guardia M, Ramos Font C, et al. Diagnosis efficacy of structural (CT) and functional (FDG-PET) imaging methods in the thoracic and extrathoracic staging of non-small cell lung cancer. Clin Transl Oncol. 2007:9(1):32-9

25. Turkmen C, Sonmezoglu K, Toker A, Yilmazbayhan D, Dilege S, Halac M, et al. The additional value of FDG PET imaging for distinguishing NO or N1 from N2 stage in preoperative staging of non-small cell lung cancer in region where the prevalence of inflammatory lung disease is high. Clin Nucl Med. 2007;32(8):607-12.

Artigo recebido: 17/08/09

Aceito para publicação: 18/02/10 